\title{
Prospecção de cenários futuros: estudo aplicado a biblioteca virtual Paul Otlet
}

\author{
Sanderli José da Silva Segundo \\ Wagner Junqueira de Araújo \\ Guilherme Ataíde Dias
}

Universidade Federal da Paraíba - UFPB, Brasil

\section{CASE REPORT}

\begin{abstract}
Resumo
Objetivo. Este trabalho discorre sobre a atuação de uma Biblioteca Virtual hospedada no Second Life e sobre esta plataforma de realidade virtual não imersiva e sua perpesctivas futuras. Apresenta levantamento sobre estudos que demonstram aplicabilidade da realidade virtual em diversas áreas do conhecimento. Discute divergências e convergências sobre o tema "bibliotecas virtuais" com base na literatura científica brasileira publicada entre 2010 e 2015 . Tendo como ponte de partida a literatura sobre o tema, o estudo prospecta três possíveis cenários futuros para a Biblioteca Virtual Paul Otlet.

Método. Utilizou-se o método de prospecção de cenários futuros, desenvolvido por Michel Godet, em cinco etapas: identificação do problema, diagnóstico da organização, identificação de variáveis e atores internos e externos, identificação das influências e dependências diretas entre variáveis e atores e elaboração de três cenários prováveis.

Resultados. Como resultado a pesquisa verificou que a formação acadêmica do profissional da informação é determinante na construção de um cenário favorável ou desfavorável às bibliotecas virtuais no Brasil.

Conclusões. A escassez de profissionais treinados em ambientes virtuais, interfere na percepção da relevância desse tipo de biblioteca, fundamentalmente tecnológica, e isso reflete em seus serviçoes e potenciais usuários.
\end{abstract}

Palavras-chave

Bibliotecas virtuais; Cenários futuros; Gestão da informação e do conhecimento; Profissional da informação

\section{Prospecting future scenarios: Study implemented to the virtual library Paul Otlet}

Abstract

Objetive. This paper discusses the future of the Paul Otlet virtual library, which is hosted in Second Life, a non-immersive virtual reality platform. It presents a survey on studies that demonstrate applicability of virtual reality in the various areas of knowledge, based on a research carried out at the Digital Thesis and Dissertation Base (bdtd.ibict.br). It discusses the divergences and convergences on virtual libraries, based on a survey in the Brazilian scientific literature about virtual libraries between 2010 and 2015. It presents brief history and activity records executed by the Paul Otlet Virtual Library. The study prospects three possible future scenarios for the Paul Otlet virtual library.

Method. Was used the method of prospecting future scenarios, developed by Michel Godet, in five stages: identification of the problem , Organization diagnosis, identification of internal and external variables and actors, identification of influences and direct dependencies between variables and actors and elaboration of three probable scenarios.

Results. As a result the research verified that the academic formation of the information professional is determinant in the construction of a favorable or unfavorable scenario to the virtual libraries in Brazil.

Conclusions. The shortage of professionals trained in virtual environments reflects on the relevance that this type of library, fundamentally technological, represents to its potential users.

Keywords

Future Scenarios; Information and Knowledge Management; Information Professional; Virtual Libraries 


\section{Introdução}

É marcante no século XXI a descontinuidade e adaptabilidade de produtos e serviços por causa do avanço das tecnologias computacionais e sua popularização. Este cenário atual, de constante evolução e mudanças, alimenta incertezas e prejudica a tomada de decisão de organizações. A leitura de tendências futuras e consecutiva antecipação de ações estratégicas, neste estágio de rápidas transições, são fundamentais para manter a competitividade organizacional (VARUM; MELO, 2009). Por exemplo, a substituição do papel e de fitas, materiais físicos, por arquivos digitais, foi fator predominante no desaparecimento, adaptação, progresso e conflitos de alguns mercados (HURST; CLOUGH, 2013).

A indústria do jornal, por exemplo, enfrentou baixas vendas de seu material impresso por causa do crescimento das mídias digitais, porém enxergou no barateamento da internet a oportunidade para potencializar faturamentos e nichos de mercado. Para isso, precisou se adaptar à um novo formato, migrando do suporte físico ao digital (KUMAR; et al., 2012). O conflito limitou a circulação física de alguns jornais e outros migraram totalmente para o formato digital, diminuindo a impressão. Nesse problemático cenário, o lançamento do tablet deu luz às investidas em gerar receita em plataformas alternativas:

Uma pesquisa do Reynolds Journalism Institute, lançada no outono de 2010, afirmava que 99\% dos usuários de iPad consumiam notícias através do dispositivo, além da experiência de consumo de notícias no iPad ser a mais parecida com a do jornal impresso. Os usuários de iPad também se mostraram menos propensos a ter (ou ao menos manter) assinaturas de jornais (KUMAR; et al., 2012, p. 06).

O mercado livreiro também aplicou mudanças em seu modo de abordar o comércio editorial, livrarias e editoras integraram livros digitais aos seus catálogos, os chamados e-books. A Amazon.com ilustra essa tendência, pois produz e comercializa equipamentos leitores da sua marca Kindle, chamados e-readers, também vende e-books legíveis em extensões proprietárias, e ainda mantém um programa de autopublicação, no qual qualquer usuário pode publicar seu e-book sem custos referentes ao processo de editoração (ARAÚJO, et. al., 2013). Outro mercado inevitavelmente adaptado foi o fotográfico, perante o barateamento das tecnologias que capturam imagens em alta definição, à diversidade de serviços gratuitos de armazenamento e compartilhamento de arquivos em nuvens, serviços de relevação e fotógrafos profissionais percebem uma menor dependência às suas atividades por parte dos consumidores que aderiram à fotografia digital (MONTEIRO, 2016).

Numa visão generalista, substituiu-se átomos por bits (NEGROPONTE, 1995) as empresas que trabalham com leitura, periódicos, revistas, livros, dentre outros, se remodelaram, algumas não abandonando seus artefatos físicos e analógicos, mas imergiram no mercado digital aumentando seu leque de atuação, como é o caso das bibliotecas, pois estas lidam essencialmente com materiais palpáveis e por isso mesmo elas também têm modificado seus produtos e serviços para atingir as necessidades dos consumidores de conteúdo digital. As mudanças geradas pela transição físico-digital-virtual ocasionam rupturas em todas as áreas, utilizando isto como pano de fundo este trabalho tem por objetivo projetar 03 possíveis cenários futuros para a Biblioteca Virtual Paul Otlet, biblioteca brasileira atuante numa plataforma de realidade virtual.

\section{Realidade virtual e a plataforma do Second Life}

O termo Realidade Virtual (RV) nasceu na década de 1980, seu pai é Jaron Lanier, músico, desenhista, escritor e cientista da computação (KRUEGER, 1991). Lanier, eleito pela revista Times em 2010, uma das 100 pessoas mais influentes do mundo, designou a tecnologia de computador que usa representações tridimensionais de terrenos, pessoas, texturas, características climáticas, móveis, veículos, roupas, acessórios pessoais dentre outros objetos, simulando ambientes reais a fim de favorecer a interatividade humano-computador através de atividades intuitivas.

Apesar de Jaron Lanier ter conceituado, Ivan Sutherland foi precursor da ideia de virtualização do real, ele juntamente com Bob Sproull, seu colega de Harvard, criou em 1968 o que é considerado primeiro Head Mounted Display (HMD), batizado por eles, na ocasião, de the sword of Damocles (MONTEIRO, 2016). Para Kirner e Siscouto (2007, p, 07), "realidade Virtual é uma interface avançada do usuário para acessar aplicações executadas no computador, propiciando a visualização, movimentação e interação do usuário, em tempo real, em ambientes tridimensionais gerados por computador". Segundo Lanier (1989, p. 110, tradução nossa1) "Virtual significa algo que existe apenas como uma representação eletrônica, não tem outra existência concreta". O fato de imitar situações corriqueiras, comuns a todos, faz com que a RV seja útil em diversos âmbitos sociais, tal 
particularidade é salientada por Lanier (1989, p. 112, tradução nossa²): "Realidade Virtual é concebida como uma expansão da realidade, a provisão de realidades alternativas para as pessoas em massa compartilharem experiências".

Há diversas atuações da realidade virtual, exemplos podem ser citados: modalidades de ensino à distância; simuladores de vôo dos cursos preparatórios; simuladores de carros das autoescolas; indústria do entretenimento com seus filmes e jogos construídos com modelagem 3D (tridimensional). O quadro 01 é produto de pesquisa feita na Biblioteca Digital de Teses e Dissertações ${ }^{3}$ (BDTD), mantida pelo Instituto Brasileiro de Informação em Ciência e Tecnologia (IBICT), que objetivou verificar teses e dissertações entre janeiro de 2015 e dezembro de 2016 que estudaram a aplicabilidade da realidade virtual em diferentes áreas de atuações:

Quadro 01 - Estudos sobre aplicabilidade da realidade virtual, entre 2015 e 2016.

\begin{tabular}{|l|c|c|}
\hline \multicolumn{1}{|c|}{ Temas abordados } & 2016 & 2015 \\
\hline Ambientes de aprendizagem: Física / Ergonomia automotiva & 2 \\
\hline Cinematografia & 1 & 1 \\
\hline Intervenção cirúrgica: Odontologia / Urologia & 1 & 1 \\
\hline Modelagem 3D & 1 & 1 \\
\hline Neuropsicologia & 1 & 4 \\
\hline $\begin{array}{l}\text { Reabilitação motora: } \\
\text { acidente vascular cerebral / paralisia cerebral }\end{array} \quad 12$ \\
\hline \multicolumn{1}{|c|}{ TOTAL } & 12 \\
\hline
\end{tabular}

Fonte: elaborado pelos autores com base nos dados coletados na BDTD, 2016.

Foram doze trabalhos coletados, utilizando por primeiro filtro a pesquisa do termo "realidade virtual" nos títulos dos trabalhos e por segundo filtro a leitura do resumo. Há grande variedade, desde ambientes preparados para potencializar o aprendizado de física à simuladores pré intervenção cirúrgica que servem para "aquecer" o médico e sua equipe, numa espécie de treinamento. Porém, todos os temas abordados, essencialmente, lidam com "aprendizagem", de forma direta ou indireta. O que coaduna com a afirmativa de que:

realidade virtual, um meio composto por simulações interativas de computador que detectam a posição e as ações do participante e substituem ou aumentam as respostas para um ou mais sentidos, dando a sensação de estar imerso ou mentalmente presente na simulação (SHERMAN; CRAIG, 2003, p. 13, tradução nossa $\left.{ }^{4}\right)$.

Em 2003 a Linden Lab lançava o Second Life ${ }^{\mathbf{5}}$ (SL), atraindo os olhares de organizações com e sem fins lucrativos. Grandes marcas instalaram sedes virtuais na plataforma, porém o custo e a complexidade de uso se tornaram dificultadores para o processo de popularização da realidade virtual na primeira década do século XXI. Mesmo com o afastamento de multinacionais, empresas $100 \%$ virtuais lograram êxito, segundo Ebbe Altberg (2015), CEO da Linden Lab, em entrevista ao portal The Next Web, o Second Life movimenta um PIB de US\$ 500 milhões de dólares americanos, e em 2015 os comerciantes sacaram, desse mercado, o equivalente a US\$ 60 milhões.

Second Life oferece uma plataforma pronta para o uso educacional avançado, com potencial para muitos tipos de simulação [...]. Ele pode fornecer atividades baseadas na exploração que sintetizam o envolvimento dinâmico e ativo, condições autênticas da aprendizagem. Também é reconhecido como um instrumento importante para complementar a formação profissional. Uma área acadêmica que normalmente usa o SL é o treinamento em design. (CAO; et al., 2014, p. 83, tradução nossa ${ }^{6}$ ).

O ambiente virtual "é povoado por objetos, os quais podem ser fixos ou móveis. Nestes últimos, encontram-se os humanos virtuais, classificados em duas categorias distintas: agentes virtuais e avatares". (MODESTO et al., 2006, p. 79). No Second Life o avatar é editável ao gosto do usuário, é possível deixá-lo mais alto, baixo, gordo, magro, e ainda mais, modificar o formato do rosto, tom de pele, cor do cabelo, cor dos olhos, roupas, acessórios, inserir tatuagens, enfim é customizável.

No Second Life o representante virtual do usuário é conhecido como avatar. O avatar inicialmente é genérico para todos os usuários, mas uma vez começamos a caminhar pelo Second Life podemos modificar absolutamente tudo [...] também podemos o transformar em um animal ou monstro. Second Life nos permite modelar o avatar ao nosso gosto (RODRÍGUEZ, 2007, p. 11, tradução nossa7). 
A plataforma adota mecanismos que regulam as diversas trocas de bens e serviços, para garantir a circulação monetária em seu mercado interno. A moeda do SL chama-se Linden Dollar (L\$) e pode ser comprada via cartão de crédito internacional no site do simulador. Até Novembro de $2016, \mathrm{~L} \$ 10,00$ lindens equivale à US $\$ 0,04$ dólar Americano, adicionando a taxa de transação que é US\$ 0,40, dez lindens custam US\$ 0,44 centavos de dólares americanos, esta quantia fica em torno de $\mathrm{R} \$ 1,50$ reais, sem contar com a cobrança do Imposto sobre Operações Financeiras (IOF). Além das transações pessoais há uma loja oficial onde construtores vendem seus objetos, Market Place (em português Mercado), nela pode-se encontrar desde acessórios a prédios complexos, caros, baratos e até gratuitos, porém percebe-se que pouco existe consumo gratuito no SL.

Cerca de 900 mil residentes utilizaram regularmente o Second Life em 2015, se o residente não tem condições financeiras para comprar uma ilha ou alugar um terreno pode experimentar ferramentas de construção nos sandboxes (caixas de areia). Essas caixas remetem à formação de esculturas de areia por crianças, amassa aqui, estica acolá, modela lá, ações básicas na modelagem virtual. São terras abertas ao público, destinadas às práticas de criação de objetos via modelagem tridimensional. Luz e Kirner (2006, p. 109) confirmam que "a criação de um objeto do mundo virtual envolve normalmente a utilização de ferramentas de modelagem tridimensional (3D), edição de imagem, som, vídeo e comportamento". A matéria prima da modelagem nos ambientes virtuais é o prim, abreviação de primitive, expressão usada para mencionar as formas geométricas. Estão disponíveis, no recurso de construção do SL, 13 prims diferentes (Figura 1):

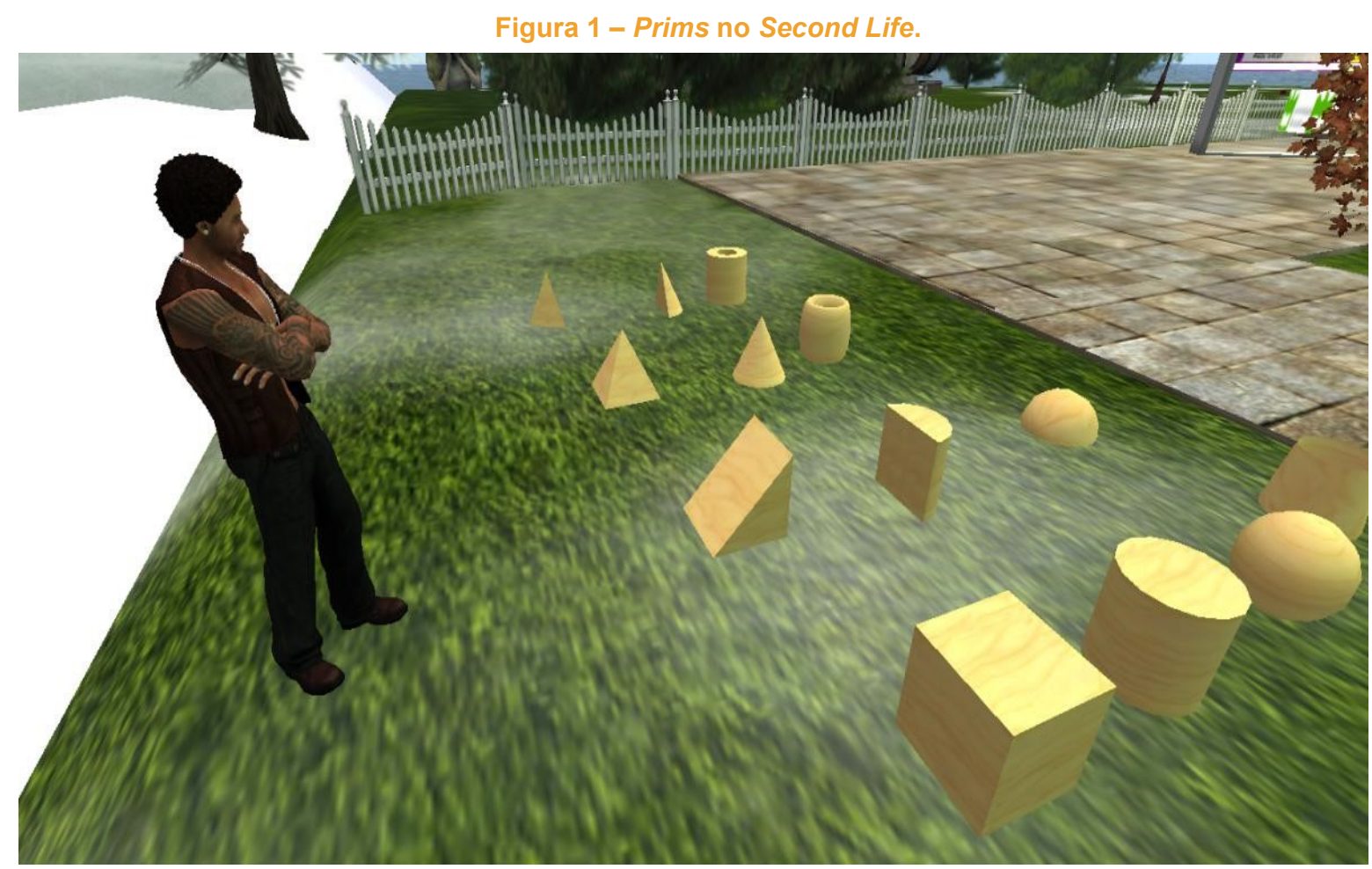

Fonte: Fotografado pelos autores no ambiente do Second Life, 2016

Cubo, Prisma, Pirâmide, Tetraedro, Cilindro, Semi-cilindro, Cone, Semi-cone, Esfera, Semi-esfera, Toróide, Tubo e Anel. Bianchini et al. (2006, p. 199) traz luz ao propósito da modelagem na RV: "a modelagem de ambientes 3D realistas é frequentemente vista como processo de alta precisão, trabalho quase mecânico no qual o importante é copiar, o mais fielmente possível, a própria estrutura dos objetos reais". A partir desta técnica, são criadas todas as organizações presentes no Second Life.

Na Collision Conference, Altberg (2016) afirmou que mais de 500 instituições de ensino atuam regularmente no Second Life. As tendências de compartilhamento dos arquivos digitais, substituição daquilo que é palpável e ensino à distância, encontram apoio no formato desenvolvido pelo SL, lá é possível conversar por chat geral ou privado e microfone, ferramentas que se comportam de maneira diferente dependendo da distância entre os usuários, por exemplo, num mesmo prédio o grupo $A$ de avatares conversa sobre matemática no $3^{\circ}$ andar de um determinado prédio, enquanto no mesmo edifício, o grupo $B$ debate literatura no $1^{\circ}$ andar, isto facilita a logística 
das salas de aula para empreendimentos de ensino. Executar áudio, assistir vídeos, ouvir músicas, utilizar websites, sem sair da plataforma, ler livros, fotografar, compartilhar arquivos textuais e audiovisuais, apresentar slides, dentre outras interações.

Para ilustrar o funcionamento dessas entidades de ensino, serão destacadas aqui duas organizações atuantes em 2016:

Figura 2 - Simpósio de Saúde Mental 2016, illha Virtual Ability, EUA.

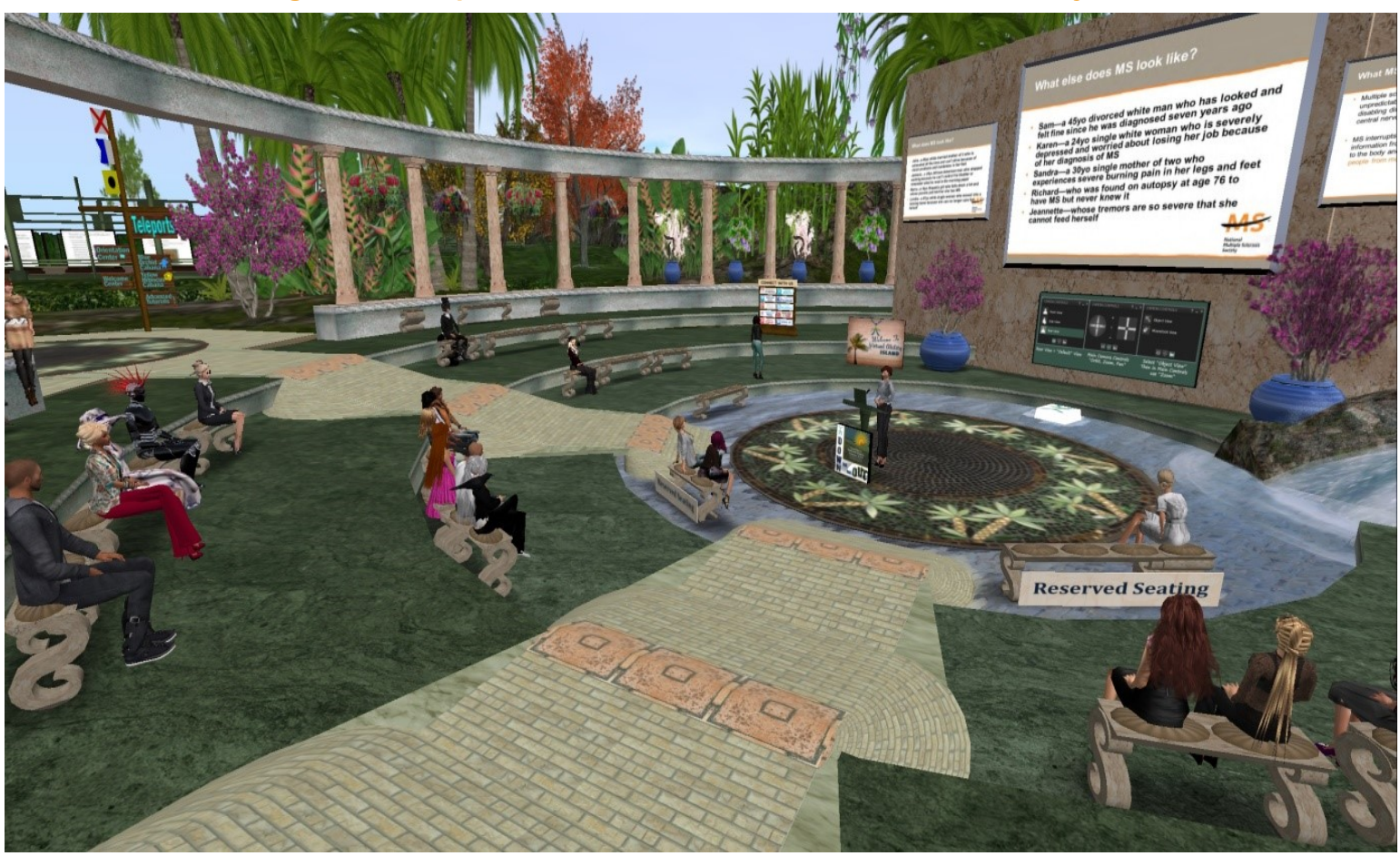

Fonte: fotografado pelos autores no ambiente do Second Life, 2016.

O Virtual $A b i l i t{ }^{8}$ é uma entidade sem fins lucrativos que funciona no Second Life desde 2007 e entre seus usuários há deficientes visuais e auditivos, outros têm funcionalidade motora reduzida por conta de acidente vascular cerebral. Desde 2012, oferece conferências na área de saúde. Quem preside essa instituição é Alice Krueger, educadora norte-americana, portadora de esclerose múltipla. A última conferência realizada dia 18 de junho de 2016, contou com 09 palestrantes. Entre eles estavam Dr. Vanja Duric, professor assistente de Fisiologia e Farmacologia da Des Moines University, em lowa, EUA, com o tema "Mecanismo cerebral ligando stress e doença". Andrea Artz, vice-presidente dos programas clínicos e serviços diretos, da cidade de New York, EUA, com o tema "Compreendendo os aspectos emocionais da esclerose múltipla. Collen Gray, CEO da Fearless Nation PTSD Support, com o tema "Hipócrates chorou: sobrevivendo psicologicamente à medicina moderna durante uma crise de saúde”. Dr. Harold Koenig, diretor do centro de espiritualidade, teologia e saúde e professor de psiquiatria e ciências comportamentais da Duke University Medical Center, EUA, também é professor adjunto do departamento de medicina da King Abdulaziz University, em Jeddah Arábia Saudita e professor adjunto do departamento de saúde pública na Ningxia Medical University, Yinchuan, China, com a palestras "Fé e saúde: pesquisa, aplicações clínicas e recursos. 
Figura 3 - Biblioteca Virtual da Bradley University, EUA.

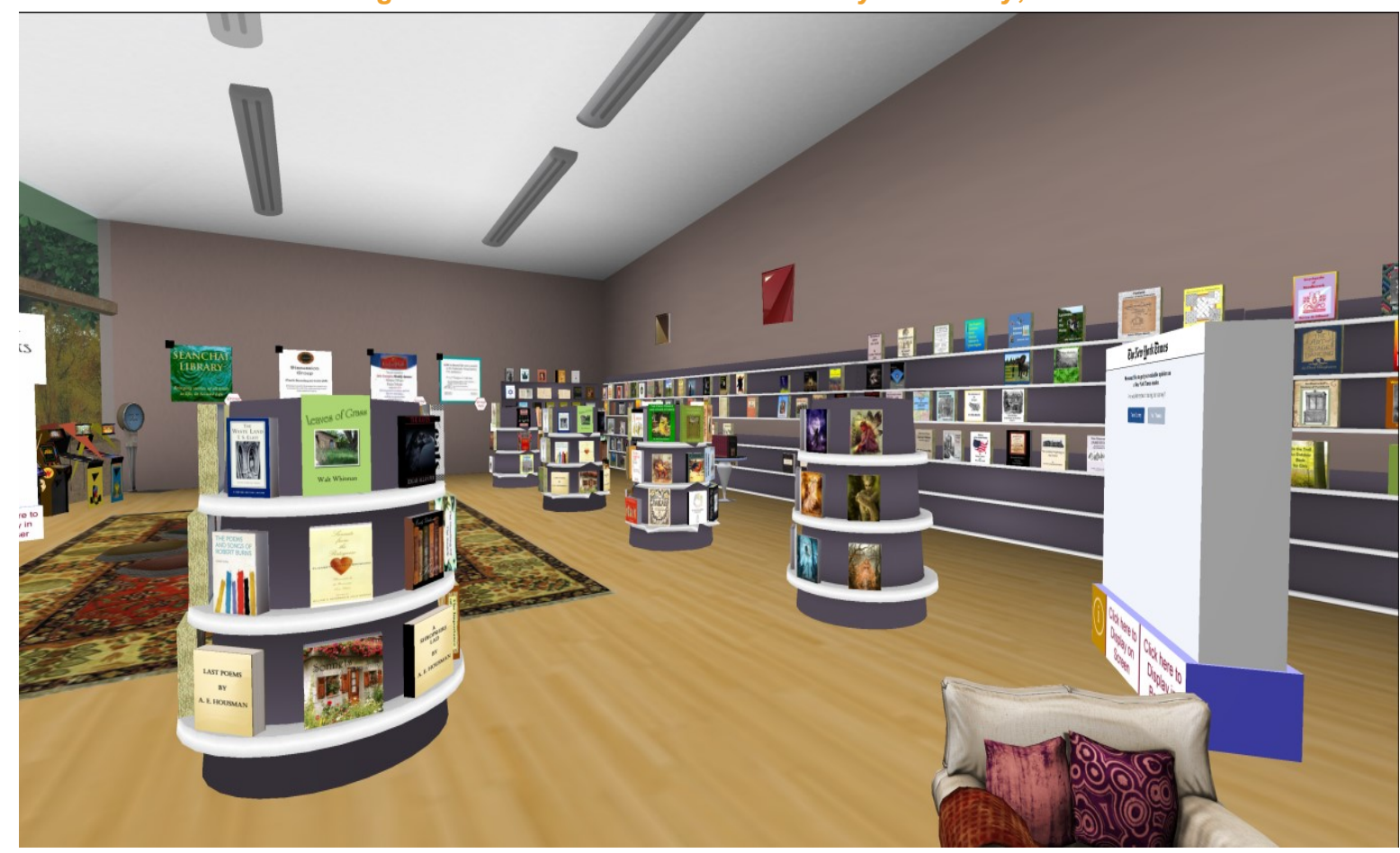

Fonte: Fotografado pelos autores no ambiente do Second Life, 2016.

A biblioteca virtual da Bradley University, EUA, funciona desde fevereiro de 2016 no Second Life, possui um cronograma diário para atendimentos e serviços de referência, através dele o usuário se programa e consegue conversar com bibliotecários. E-books, audio books e eventos para encontros casuais entre os usuários e discussões literárias são os serviços oferecidos pelo ambiente.

\section{Prospecção de cenários futuros para a Biblioteca Virtual Paul Otlet}

Preparar os gestores para saber o fazer enquanto as mudanças acontecem é uma das funcionalidades da prospecção de cenários futuros, este recurso potencializa a reflexão sobre causas que modificam o futuro, confronta a zona de conforto e alimenta estrategicamente o processo decisório da organização, preparando-a contra possíveis ataques à continuidade de suas atividades (WULF, 2015). Antecipação de cenários é uma ferramenta para produção de informação estratégica e usada pelas disciplinas de gestão estratégica, com efeitos a longo prazo, algumas vezes negligenciada em grandes, médias e pequenas organizações, porque, segundo Godet (2000) quando os objetivos da empresa estão sendo alcançados é possível gerenciar, à curto prazo, sem se preocupar com potenciais descontinuidades e quando os objetivos se tornam difíceis e inatingíveis os gestores precisam adotar ações rápidas, de curto efeito, fundamentalmente reativas. O método não objetiva prever o futuro mas, verificar tendências lógicas de futuros possíveis, através da análise comportamental do seu objeto estudado mediante interação de variáveis e atores (BUARQUE, 2003), seu foco, de acordo com Moritz (2004, p. 49) é "estudar as diversas possibilidades de futuros plausíveis existentes e preparar as organizações para enfrentar qualquer uma delas, ou até mesmo criar condições para que modifiquem suas probabilidades de ocorrência, ou minimizar seus efeitos". Conforme Godet e Durance (2011), não existe um futuro predestinado do qual a organização possa extrair respostas assertivas. Para eles o futuro é construído, indeterminado e múltiplo, ou seja, há outros futuros prováveis com chances de assumir o status de futuro. As transformações sociais, econômicas e políticas desenham futuros diversos, dependendo da movimentação de suas variáveis.

Em áreas nas quais as mudanças pouco influenciam o comportamento de produtores e consumidores de determinado produto ou serviço, o planejamento adotado, comumente, dispensa rigor ao processo de antecipação de futuro, porém, quando as mudanças contextuais influenciam a forma da produção e consumo, organizações que lidam com o método maximizam suas capacidades adaptativas e de conservação (BUARQUE, 2003). Quando uma organização inicia o processo estratégico com finalidade de desenvolver 
cenários futuros é porque reconhece que os efeitos vindouros são imprevisíveis em sua totalidade, porém são adaptáveis e podem ser convertidos em favor dos objetivos organizacionais (WRIGHT, 2005).

No processo de desenvolvimento de cenários futuros para a Biblioteca Virtual Paul Otlet, utilizou-se 05 etapas, baseadas no método de prospecção de cenários desenvolvidos por Godet e Durance (2011, p. 27), as quais foram:

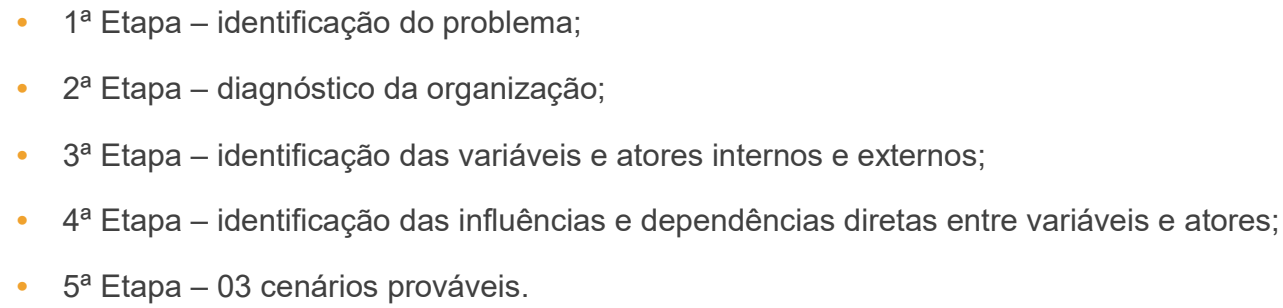

A equipe responsável por aplicar o método prospectivo, seguindo esses cinco passos, foi formada por especialistas em Ciência da Informação, sendo eles 01 Doutor, 03 Doutorandos e 03 Mestrandos em Ciência da Informação. Que desenvolveram esta análise durante a disciplina "Gerenciamento Estratégico da Informação", ministrada em 2016.2, ofertada pelo Programa de Pós-Graduação em Ciência da Informação, na Universidade Federal da Paraíba. O objetivo foi traçar 03 cenários diferentes, tendo por base os gráficos resultantes das matrizes de influência direta entre variáveis e atores, geradas pelos softwares MICMAC e MACTOR, desenvolvidos por Michel Godet.

\subsection{Identificação do problema}

Para à identificação do problema, verificou-se a produção da área da Ciência da Informação brasileira sobre biblioteca virtual, com intuito de abordar o que tem sido considerado biblioteca virtual na literatura científica da área. A pesquisa foi realizada na Base de Dados Referenciais de Artigos e Periódicos em Ciência da Informação $\left(\mathrm{BRAPCl}{ }^{9}\right)$, em dezembro de 2016 e até esta data a base indexava 53 revistas científicas brasileiras. Para o processo de coleta utilizou-se o filtro "palavras-chave". A busca envolveu termos relativos às bibliotecas virtuais, os quais foram "biblioteca virtual", "ambiente virtual", utilizados na forma singular e plural, e "realidade virtual", utilizado no singular, resultando em 05 possibilidades de recuperação. Identificou-se 03 artigos publicados em 2010, 05 em 2011, 04 em 2012, 08 em 2013, 03 em 2014 e 03 em 2015. Totalizando 26 textos coletados, excluindo-se 01 por duplicidade, obteve-se 25 artigos. O gráfico 01 exibe quais palavras-chave se apresentaram com maior recorrência:

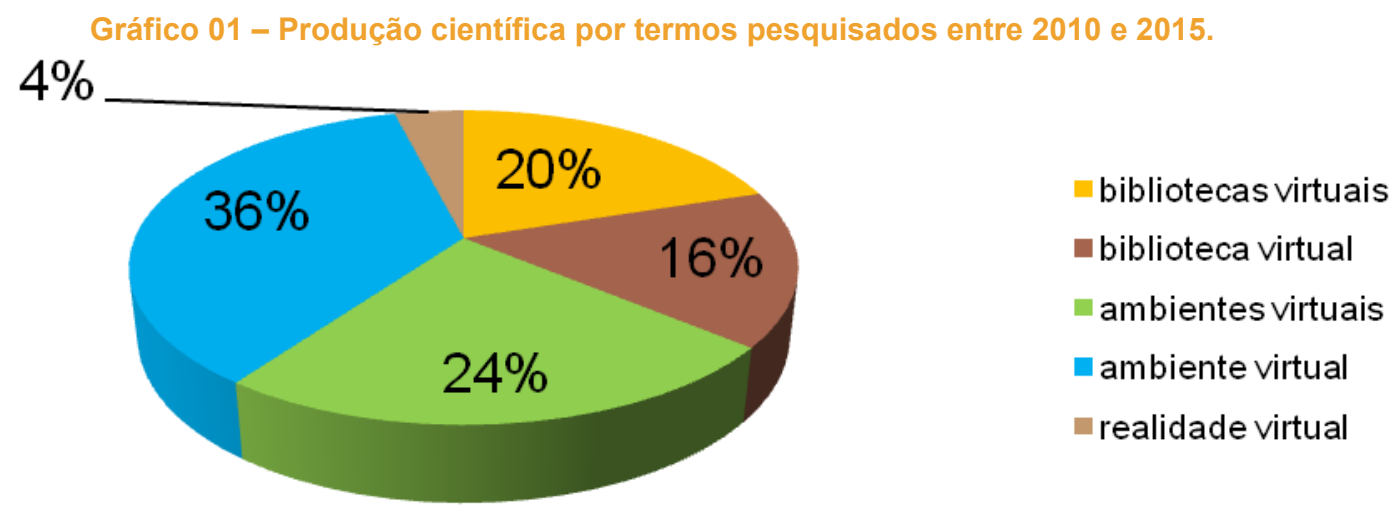

Fonte: elaborado pelos autores com base nos dados coletados na BRAPCI, 2016.

Em seguida, separou-se o que se tratava de ambientes digitais, tais como repositórios, ambientes de aprendizagem e serviços digitais integrados à bibliotecas físicas dos que tratavam de ambientes virtuais, ou seja, estudos que consideravam a possibilidade de atuação em plataformas de realidade virtual, conforme gráfico 02. 
Gráfico 02 - Produção científica por assuntos abordados entre 2010 e 2015.

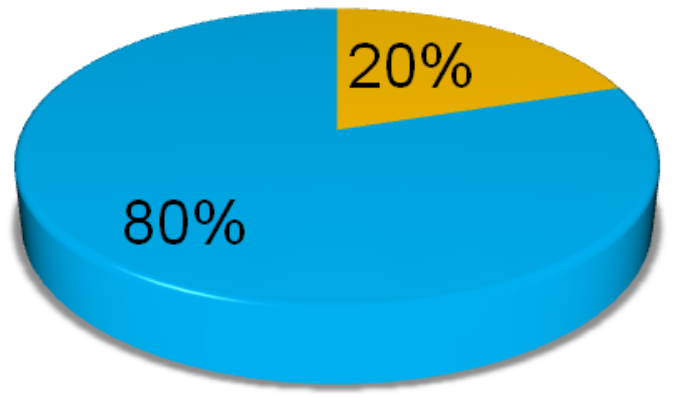

$\square$ ambientes virtuais

$\square$ ambientes digitais

Fonte: elaborado pelos autores com base nos dados coletados na BRAPCI, 2016.

O resultado mostrou que as bibliotecas virtuais têm encontrado desafios tanto teóricos quanto práticos. Há disparidade na literatura brasileira quanto à conceituação dos termos "virtual" e "digital". Dos 25 trabalhos identificados entre 2010 e 2016 que trataram sobre bibliotecas virtuais, 80\% deles são estudos sobre bibliotecas digitais ancorados numa literatura que utiliza o termo virtual para tratar de repositórios digitais. Apenas $20 \%$ dos trabalhos utilizaram o termo virtual para tratar de técnicas relativas à realidade virtual voltadas às bibliotecas virtuais e atuação de bibliotecários nestes ambientes. Conforme Thomas Kuhn (1998) enquanto um paradigma não encontra consenso na comunidade científica, os instrumentos e conceitos proporcionados por ele são resistidos e atacados formando uma crise teórica.

Porém, mesmo tendo uma produção científica quantitativamente maior, bibliotecas digitais encontram resistência nas grades curriculares dos cursos brasileiros de biblioteconomia. Em pesquisa recente, Madureira e Vilarinho (2010) analisaram como os cursos brasileiros de biblioteconomia preparam os futuros bibliotecários para atuarem em bibliotecas digitais. A pesquisa abordou bibliotecários experientes e recém formados, apenas $41 \%$ dos profissionais experientes consideraram satisfatória a formação recebida, enfatizando que os conteúdos essenciais são oferecidos:

de um modo geral, as universidades não oferecem a capacitação necessária para o trabalho com as tecnologias, no entanto, ensinam a lógica necessária aos processos de seleção, organização, atualização, depuração, armazenamento e divulgação dos dados, o que constitui a base das atividades desse profissional. O conhecimento prático vem depois com a experiência profissional e a realização de cursos de atualização (MADUREIRA; VILARINHO, 2010, p. 98).

Quanto aos recém formados, a maior parte deles disseram que as poucas disciplinas sobre tecnologia da informação e comunicação não têm biblioteca digital como foco e que elas "abordam a questão de forma transversal, o que torna o conteúdo superficial, incompleto e fragmentado" (MADUREIRA; VILARINHO, 2010, p. 98). Destacaram também a ênfase nas aulas teóricas em detrimento de aulas práticas e apontaram que inexiste estágio supervisionado em bibliotecas digitais. Os pesquisadores consideram que se há uma lacuna na formação do bibliotecário em relação às bibliotecas digitais, este déficit é ainda maior quando se trata das tecnologias da realidade virtual (MADUREIRA; VILARINHO, 2010).

Não obstante problemas acadêmicos, o Brasil possui a maior carga tributária da América Latina e Caribe (EXAME, 2016). Equipamentos tecnológicos, são encarecidos e inacessíveis para parte da população. Pesquisa recente do $\operatorname{IBGE}(\mathrm{G} 1,2016)$ mostra que a produção do setor de eletrônicos e informática caiu $31,1 \%$ se comparado o $1^{\circ}$ trimestre de 2016 ao de 2015. A baixa na produção é efeito da queda de poder de consumo do brasileiro, em contrapartida, a manutenção de acesso à ambientes virtuais demandam razoável tecnologia e acesso à internet banda larga.

Além dos desafios teóricos, práticos e econômicos há também modificações nas tendências de uso tecnológico. Especificamente a Biblioteca Virtual Paul Otlet precisará se adaptar e possivelmente migrar para o mais novo projeto da Linden Lab, chamado Sansar, previsto para ser lançado em 2017 (LINDEN LAB, 2016). Sansar é considerado substituto do Second Life, e segundo seu diretor executivo Ebbe Altberg (2015), terá adaptabilidade aos dispositivos móveis, funcionalidade indisponível no SL. Outra ferramenta que vem se popularizando é a realidade aumentada, através de softwares como o Pokemon Go, da Nintendo, e equipamentos de projeção holográfica como o Hololens, da Microsoft, essa tendência pode afetar o interesse por realidade virtual não 
imersiva. Dado estes cenários, elaborou-se a seguinte questão: conseguirá a Biblioteca Virtual Paul Otlet continuar atuando em ambiente de realidade virtual e ganhar notoriedade?

\subsection{Diagnóstico}

A Biblioteca Virtual Paul Otlet funciona desde 2013 na plataforma do Second Life. Inicialmente construída em 2012 com os recursos gratuitos fornecidos por um sandbox de acesso aberto, a biblioteca logo sentiu a necessidade de alugar um terreno para garantir acesso permanente aos seus usuários e facilitar sua recuperação no sistema de busca do SL. Entre janeiro de 2013 e novembro de 2016, ela realizou 18 eventos abordando temas culturais, literários, étnicos, de conscientização social, contra a violência e sediando aulas e ou palestras acadêmicas e promovendo a experiência não imersiva para alunos de universidades públicas federais brasileiras:

Quadro 02 - Eventos sediados na Biblioteca Virtual Paul Otlet, entre 2013 e 2016.

\begin{tabular}{|l|c|}
\hline \multicolumn{1}{|c|}{ Títullo do evento } & Data \\
\hline Noite de Poesia Minimalista & $31 / 07 / 2013$ \\
\hline Exposição: 11 de Setembro & $11 / 10 / 2013$ \\
\hline Noite de Poesia Concretista & $11 / 10 / 2013$ \\
\hline Aula de Imersão - Semana Nacional de Ciência e Tecnologia - Biblioteca Central da UFPB & $22 / 10 / 2013$ \\
\hline Noite do Conto Edgar Allan Poe & $13 / 11 / 2013$ \\
\hline Noite do Conto Fantástico & $27 / 11 / 2013$ \\
\hline Palestra: Second Life, que futuro? - Palestrante Paula Justiça & $29 / 01 / 2014$ \\
\hline Exposição: Preto e Branco & $21 / 03 / 2014$ \\
\hline Palestra - Comunidades: solidariedade e discriminação - Palestrante Ana Duarte & $09 / 04 / 2014$ \\
\hline Aula Virtual - Disciplina Tecnologia da Informação II - curso Biblioteconomia - UFPB & $27 / 05 / 2014$ \\
\hline Aula Virtual - Disciplina Fontes da Informação II - curso Biblioteconomia - UFAL & $07 / 07 / 2014$ \\
\hline Exposição: Não à violência doméstica & $27 / 05 / 2016$ \\
\hline Cinema: As criadas - Jean Genet & $20 / 07 / 2016$ \\
\hline Exposição: Paz Mundial & $09 / 09 / 2016$ \\
\hline Noite de poesia Lau Siqueira & $12 / 10 / 2016$ \\
\hline Aula Virtual - Disciplina Tecnologia da Informação II - curso Biblioteconomia - UFPB & $31 / 10 / 2016$ \\
\hline Aula Virtual - Disciplina Tecnologia da Informação - curso Arquivologia - UFPB & $04 / 11 / 2016$ \\
\hline Noite de poesia Sergio de Castro Pinto & $09 / 11 / 2016$ \\
\hline
\end{tabular}

Fonte: elaborado pelos autores com base nas informações da fanpage.

Seu principal serviço são os eventos, e por isso conta com auditório (figura 4) habilitado para executar conteúdo multimídia, ali os palestrantes, professores ou mediadores, se posicionam à frente do público e ministram conteúdos específicos, previamente acordados e divulgados na fanpage ${ }^{10}$ da biblioteca. Em geral conversam por microfone e quando algum avatar espectador precisa questionar ele levanta a mão e espera sua vez. As interações seguem as convenções tradicionais e isto facilita a assimilação de ferramenta por novos usuários. 
Figura 4 - Auditório da Biblioteca Virtual Paul Otlet.

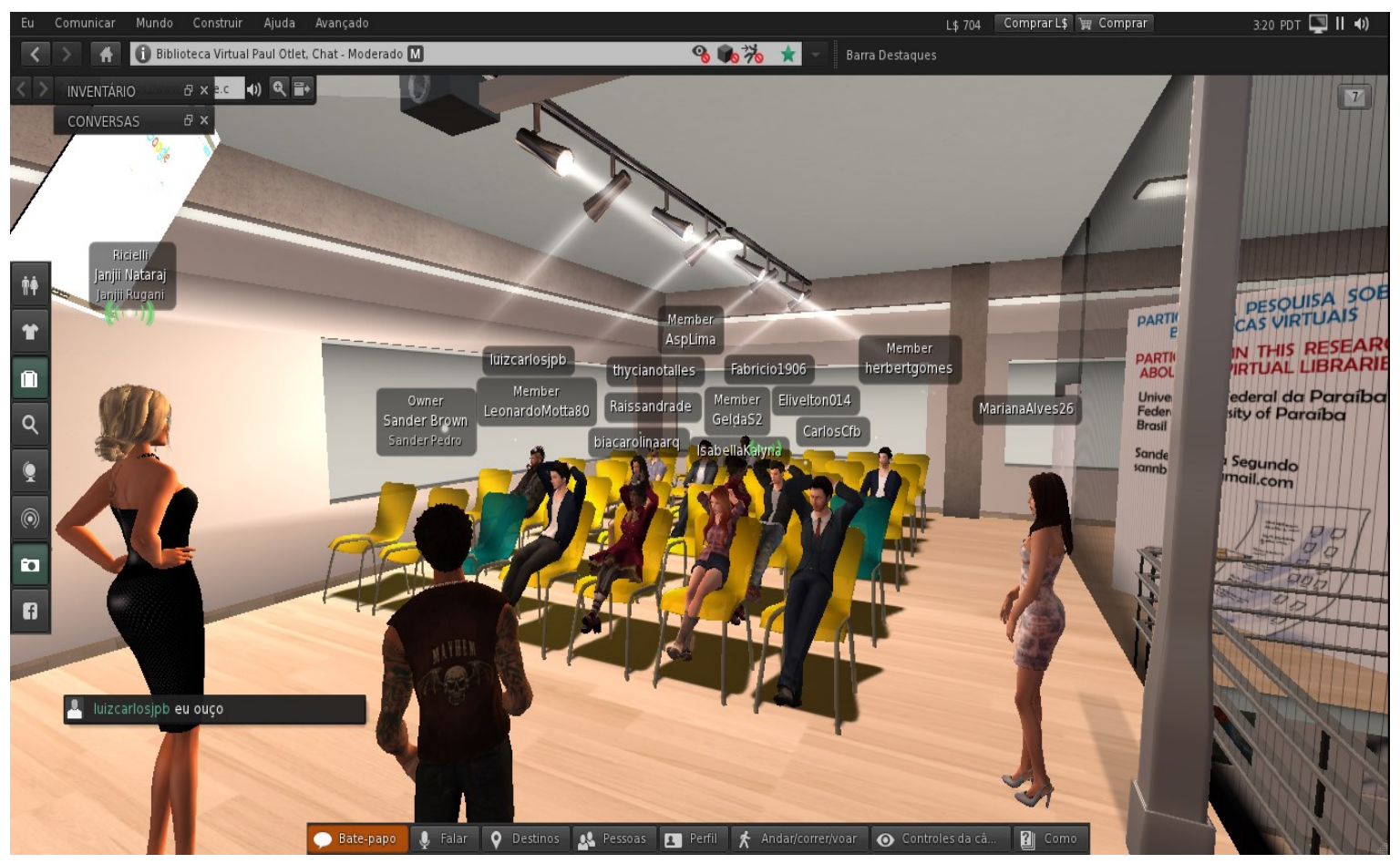

Fonte: Fotografado pelos autores no ambiente da Biblioteca Virtual Paul Otlet, 2016.

No quadro 03 são descritos os pontos basilares que norteiam o planejamento da biblioteca em análise:

Quadro 03 - Missão, visão e valores da Biblioteca Virtual Paul Otlet.

\begin{tabular}{|c|c|}
\hline $\begin{array}{l}\text { Macro } \\
\text { ambiente }\end{array}$ & Second Life \\
\hline $\begin{array}{l}\text { Micro } \\
\text { ambiente }\end{array}$ & Biblioteca Virtual Paul Otlet \\
\hline Missão & $\begin{array}{l}\text { Contribuir para a construção de um mundo pacífico, fraterno e igualitários, disseminando e } \\
\text { estimulando o acesso à informação, promovendo palestras, exposições culturais e debates, } \\
\text { subsidiando o desenvolvimento humano. }\end{array}$ \\
\hline Visão & Estar entre as melhores bibliotecas de realidade virtual não imersiva até 2020 \\
\hline Valores & $\begin{array}{ll} & \text { Democratização do acesso à informação; } \\
\text { - } & \text { Responsabilidade na produção e disseminação do conhecimento; } \\
\text { - } \quad \text { Integração fraterna entre os povos; } \\
\text { - } \quad \text { Transformação social e ética; } \\
\text { - } \quad \text { Pacificação mundial através de integrações culturais. }\end{array}$ \\
\hline
\end{tabular}

Fonte: Biblioteca Virtual Paul Otlet, 2016.

\subsection{Variáveis e atores, internos e externos}

A identificação das variáveis e atores internos e externos constitui etapa elementar para o desenvolvimento da prospecção, sem esse fundamento não é possível saber quais fatores influenciarão o nascedouro de cenários prováveis. Segundo Godet e Durance (2011, p. 63) "a explicitação detalhada de cada variável é indispensável, facilitando a análise e a identificação das relações entre as variáveis, além de permitir a constituição da base necessária a qualquer reflexão prospectiva". No quadro 04 estão elencadas as variáveis internas e externas: 
Quadro 04 - Variáveis internas e externas, Biblioteca Virtual Paul Otlet, 2016

\begin{tabular}{|l|l|}
\hline \multicolumn{2}{|c|}{ Variáveis Internas } \\
\hline Necessidade & $\begin{array}{l}\text { Relevância da atuação da biblioteca Paul Otlet em detrimento da atuação de bibliotecas } \\
\text { tradicionais e digitais. }\end{array}$ \\
\hline Competência & $\begin{array}{l}\text { Retenção e multiplicação do conhecimento organizacional pela administração da } \\
\text { biblioteca, constituída por 01 bibliotecário e 01 consultor. }\end{array}$ \\
\hline Atendimento & $\begin{array}{l}\text { Demanda e oferta por atendimento. Não há equipe de atendimento, pois apenas o } \\
\text { bibliotecário exerce essa função. }\end{array}$ \\
\hline Cooperação & $\begin{array}{l}\text { Ritmo de crescimento de cooperação com outras organizações. Parcerias para doações, } \\
\text { divulgação e marketing. }\end{array}$ \\
\hline Serviços & $\begin{array}{l}\text { Oferta de produtos e serviços virtuais. Formas de divulgação dos produtos e serviços. } \\
\text { Eventos programados. }\end{array}$ \\
\hline Integridade & Vulnerabilidade da plataforma. Ataques de avatares. Filtros de segurança. \\
\hline Futuro & $\begin{array}{l}\text { Biblioteca pretende ser reconhecida entre as melhores em realidade virtual nos próximos } \\
\text { 05 anos. Nova plataforma virtual da Linden Lab implicará provável adequação ou } \\
\text { migração. Realidade aumentada poderá impor modificações nos produtos e serviços } \\
\text { oferecidos. }\end{array}$ \\
\hline Economia & Recessão econômica e alta carga tributária brasileira. \\
\hline Formação & $\begin{array}{l}\text { Produção científica denota que não há uma formação acadêmica voltada à atuação do } \\
\text { bibliotecário em ambientes de realidade virtual. }\end{array}$ \\
\hline Cultura & Familiaridade do usuário com uma plataforma não popularizada. \\
\hline Legislação & $\begin{array}{l}\text { Regulamentações quanto à atuação de organizaçães sem fins lucrativos em ambientes } \\
\text { de realidade virtual. Restrição de faixa etária menor que 18 anos, imposta pelo Second } \\
\text { Life. }\end{array}$ \\
\hline Bibliotecas virtuais atuantes no Second Life. \\
\hline
\end{tabular}

Fonte: elaborado pelos membros da equipe de prospecção, 2016.

Traçada as variáveis, é possível identificar os atores que influenciam direta ou indiretamente e quais são condicionantes para o alcance dos objetivos organizacionais, qual tipo de interação e força exercem entre si. "A partir desta análise, o objectivo da utilização do método é fornecer a um determinado actor formas de apoio à decisão para a implementação da sua política de alianças e conflitos" (GODET; DURANCE, 2011, p. 69). O quadro 05 descreve os autores internos e externos identificados durante o processo:

Quadro 05 - Atores internos e externos, Biblioteca Virtual Paul Otlet, 2016.

\begin{tabular}{|l|l|}
\hline \multicolumn{2}{|l|}{ Atores internos } \\
\hline Equipe & Formada por 01 bibliotecário e 01 consultor. \\
\hline Bibliotecário & Exerce função de administração geral, operacionalização e atendimento. \\
\hline Consultor & Presta consultoria administrativa voltada à inovação dos produtos e serviços. \\
\hline Palestrante & Colaboradores sem vínculos empregatícios que ministram palestras. \\
\hline Pesquisador & Pesquisas científicas desenvolvidas envolvendo a biblioteca virtual Paul Otlet. \\
\hline Parceiro & Grupos da cena cultural que utilizam o espaço da biblioteca para promover eventos. \\
\hline & \multicolumn{1}{|c|}{ Atores externos } \\
\hline Usuário & Utilizadores dos serviços da biblioteca e visitantes. \\
\hline Professor & Professores universitários que promovem a utilização de bibliotecas virtuais. \\
\hline Doador & $\begin{array}{l}\text { Usuários da plataforma Second Life que identificam na atuação da biblioteca virtual } \\
\text { uma fonte segura para receber e destinar à comunidade recursos advindos de } \\
\text { filantropia. }\end{array}$ \\
\hline Concorrente & Bibliotecas virtuais atuantes no Second Life. \\
\hline Fornececor & Vendedores de objetos tridimensionais, mobília, prédios, texturas, scripts e etc. \\
\hline Academia & $\begin{array}{l}\text { Corpo docente que decide sobre a grade curricular dos cursos de biblioteconomia do } \\
\text { Brasil e por conseguinte influência a formação dos profissionais bibliotecários. }\end{array}$ \\
\hline
\end{tabular}

Fonte: elaborado pelos membros da equipe de prospecção, 2016. 
Reconhecidos as variáveis e atores, distribuiu-se pesos concernentes à cada elemento, numa escala de 1 a 5 que representa o nível de influência, capaz de comprometer a continuidade das atividades da biblioteca virtual. Quanto menor for o número, pouca influência exerce, quanto maior for, mais influente é o elemento.

Quadro 06 - Atribuição de pesos individuais às variáveis e atores.

\begin{tabular}{|c|c|c|c|}
\hline Variáveis internas & Peso & Variáveis externas & Peso \\
\hline Necessidade & 4 & Futuro & 5 \\
\hline Competência & 2 & Economia & 2 \\
\hline Atendimento & 3 & Formação & 5 \\
\hline Cooperação & 2 & Cultura & 4 \\
\hline Serviços & 5 & Legislação & 1 \\
\hline Integridade & 1 & Concorrência & 2 \\
\hline Atores internos & Peso & Atores externos & Peso \\
\hline Equipe & 3 & Usuários & 5 \\
\hline Bibliotecário virtual & 4 & Professores & 5 \\
\hline Consultor & 3 & Doadores & 2 \\
\hline Palestrante & 5 & Concorrentes & 2 \\
\hline Pesquisador & 3 & Fornecedores & 1 \\
\hline Parceiro & 3 & Academia & 5 \\
\hline
\end{tabular}

Fonte: elaborado pelos membros da equipe de prospecção, 2016.

Os pesos indicados levam em consideração as barreiras elencadas na fase de identificação do problema, impasses teóricos na definição do que é e como funciona uma biblioteca virtual, desatualização da matriz curricular dos programas pedagógicos dos cursos de biblioteconomia no Brasil e quando se refere aos avanços tecnológicos, o baixo poder aquisitivo da população brasileira, inviabilizando o consumo de equipamentos adequados à realidade virtual e a substituição da plataforma Second Life. Então maior peso é atribuído às variáveis e atores que mais comprometem, favorecendo ou desfavorecendo, o funcionamento da biblioteca virtual.

\subsection{Influências e dependências diretas entre variáveis}

Nesta fase, cada membro da equipe de prospecção recebeu a matriz de influências diretas em branco. Com intuito de apontar um resultado consensual, solicitou-se o preenchimento individual das matrizes, tendo por embasamento as etapas anteriores (quadro 07). Cinco valores ficaram disponíveis para preenchimento, quanto maior o valor mais forte é o nível de influência exercido entre as variáveis. Por exemplo, os membros entenderam que a "necessidade" de existência e atuação da biblioteca virtual recebe forte influência do processo de formação profissional de bibliotecários, englobando professores, coordenações e matrizes curriculares resultando na produção científica da área. Ou seja, o nível de relevância desse tipo de biblioteca é refletido na produção científica que neste estudo indicou haver conflito teórico em $80 \%$ dos artigos alvos desta pesquisa. As influências diretas são classificadas em 0 - sem influência direta - , 1 - nível de influência direta fraco - , 2 nível de influência direta médio - , 3 - nível de influência direta forte - e P - nível de influência direta potencial. 
Quadiro 07 - Matriz de Influências Diretas, Variáveis

\begin{tabular}{|c|c|c|c|c|c|c|c|c|c|c|c|c|}
\hline & 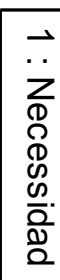 & 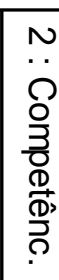 & 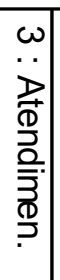 & 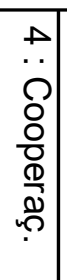 & 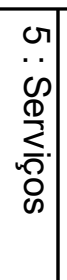 & 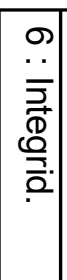 & 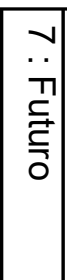 & $\mid \begin{array}{c}\infty \\
\cdots \\
m \\
0 \\
0 \\
0 \\
0 \\
0 \\
0 \\
0\end{array}$ & 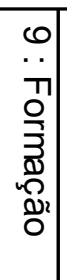 & 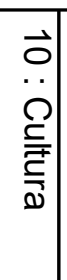 & 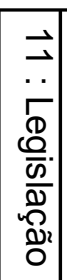 & 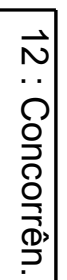 \\
\hline $1: \mathrm{Nec}$ & 0 & 3 & 3 & 2 & 3 & 0 & 3 & 3 & 3 & 2 & 2 & 3 \\
\hline 2 : Competênc. & 0 & 0 & 3 & 2 & 2 & 2 & 2 & 0 & 0 & 2 & 0 & 1 \\
\hline 3: Atendimen & 1 & 0 & 0 & 2 & 2 & 0 & 1 & 0 & 0 & 1 & 0 & 3 \\
\hline 4: Cooperac. & 2 & 0 & 0 & 0 & 3 & 0 & 3 & 0 & 0 & 0 & 0 & 2 \\
\hline 5 : Serviços & 3 & 1 & 3 & 3 & 0 & 0 & 3 & 2 & 2 & 3 & 2 & 3 \\
\hline 6 : Integrid. & 0 & 0 & 1 & 0 & 3 & 0 & 3 & 0 & 0 & 0 & 0 & 3 \\
\hline $7:$ Futuro & 3 & 3 & 3 & 3 & 3 & 2 & 0 & 3 & 3 & 3 & 3 & 3 \\
\hline 8: Economia & 2 & 0 & 0 & 3 & 2 & 0 & 3 & 0 & 2 & 2 & 2 & 2 \\
\hline 9: Formação & 3 & 3 & 2 & 0 & 3 & 2 & 3 & 3 & 0 & 3 & 3 & 2 \\
\hline 10: Cultura & 3 & 2 & 2 & 0 & 3 & 1 & 3 & 2 & 2 & 0 & 2 & 2 \\
\hline 11 : Legislação & 2 & 0 & 0 & 0 & 2 & 1 & 2 & 3 & 2 & 0 & 0 & 2 \\
\hline 12: Concorrên & 3 & 0 & 2 & 3 & 3 & 0 & 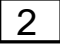 & 0 & 0 & 0 & 0 & 0 \\
\hline
\end{tabular}

Fonte: elaborado pelos membros da equipe de prospecção com auxílio do software MICMAC, 2016.

Verificada e minimizadas as divergências, o estabelecimento de pesos relacionais entre as variáveis possibilita que o software MICMAC, produza o mapa de influências e dependências diretas entre as variáveis:

Gráfico 03 - Influências e dependências diretas entre variáveis.

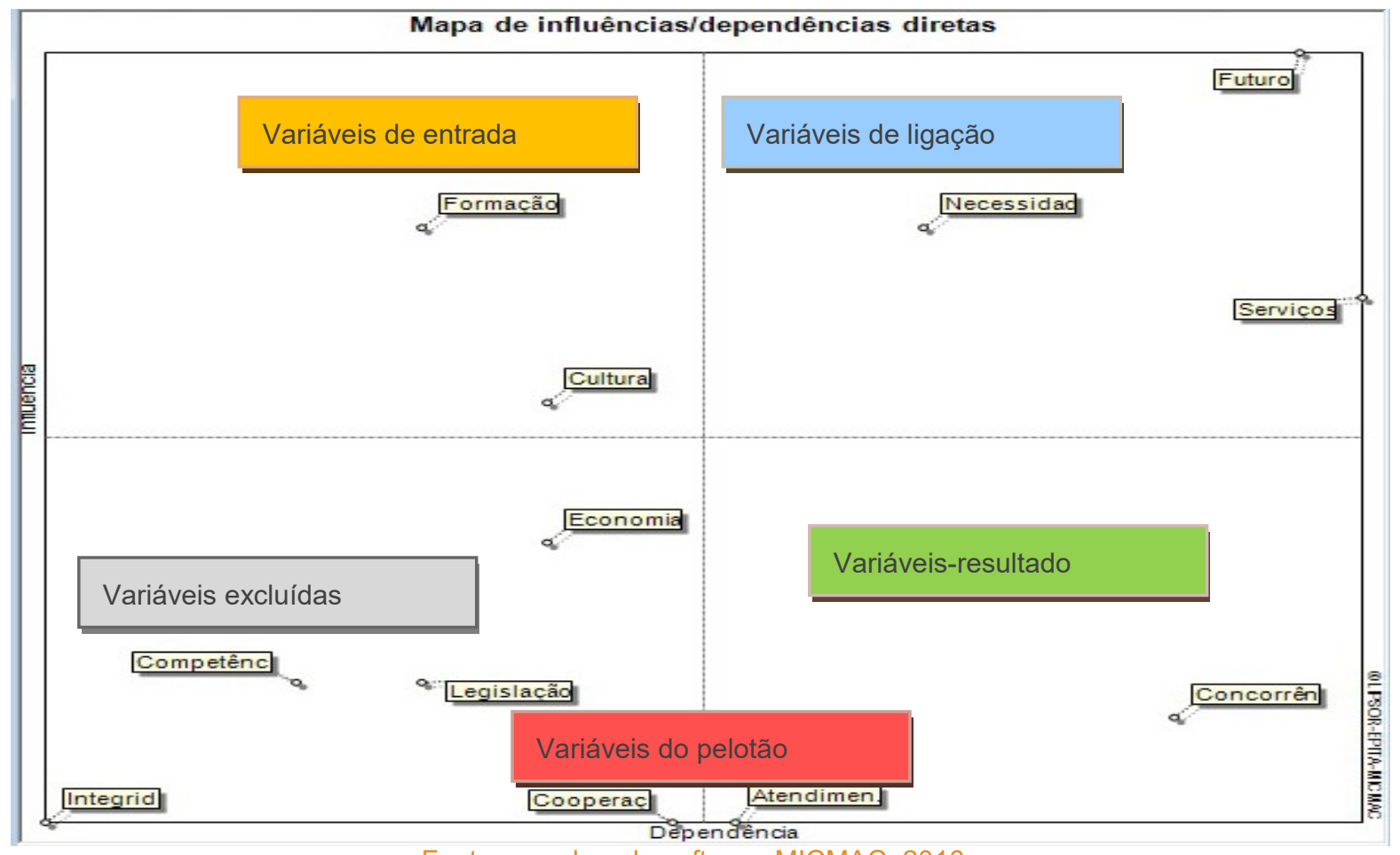

Fonte: gerado pelo software MICMAC, 2016

Cinco indicadores distinguem as variáveis através de seus posicionamentos no plano. Conforme Godet e Durance (2011). Variáveis de entrada são muito influentes e pouco dependentes, por isso se tornam alvo de ações prioritárias: formação e cultura. Variáveis de ligação têm por característica a instabilidade e são muito influentes e muito dependentes, ou seja, elas têm potencial para modificar toda a dinâmica do sistema, são elas: futuro, necessidade e serviços. Variáveis-resultado são pouco influentes, porém muito dependentes e resultam 
da influência de outras variáveis sobre elas: concorrência. As variáveis do pelotão não possuem características que as enquadrem entre influentes e dependentes: cooperação e atendimento. E por fim, as variáveis excluídas não oferecem representatividade considerada essencial para influenciar o sistema relacional: competência, legislação integridade e economia.

Um dos motivos de interesse da análise estrutural consiste em permitir a verificação das hipóteses formuladas por um grupo sobre a explicação do funcionamento do sistema. De facto, ela ajuda a confirmar se as variáveis julgadas importantes são explicativas (variáveis de entrada) ou explicadas por outras (variáveis-resultado). (GODET; DURANCE. 2011, p. 66)

Tratamento similar foi dado ao processo de preenchimento da Matriz de Influências Diretas dos Atores (quadro 08). Buscou-se consonância entre os membros da equipe de prospecção. As opções de preenchimento também alternaram entre cinco valores. Quanto maior o valor atribuído à determinada relação entre atores, maior é a força exercida. Ilustrando isso, os membros concederam peso máximo, valor 04, para a relação entre bibliotecário e usuários, dentro desta concepção para existir bibliotecário é necessário haver usuário. As influências diretas são classificadas em 0 - pouca ou nenhuma influência sobre outro ator - , 1 - o ator pode influenciar de modo limitado os processos operacionais da gestão do outro ator - , 2 - o ator pode influenciar a execução dos projetos do outro ator - , 3 - o ator influencia no cumprimento das objetivos do outro ator - e 4 - o ator influencia na existência do outro ator.

Quadro 08 - Matriz de Influências Diretas, Atores.

\begin{tabular}{|c|c|c|c|c|c|c|c|c|c|c|c|c|}
\hline MID & 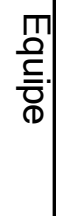 & 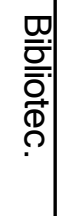 & 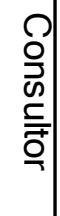 & $\begin{array}{l}\square \\
\stackrel{D}{\mathbb{D}} \\
\stackrel{\mathbb{D}}{\vec{D}} \\
\stackrel{?}{?}\end{array}$ & $\begin{array}{l}0 \\
\mathbb{D} \\
\text { Dी } \\
\text { E. } \\
0 \\
0\end{array}$ & 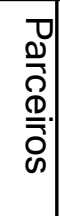 & 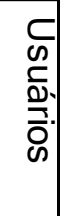 & 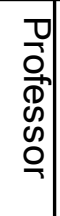 & $\begin{array}{l}\square \\
\text { 잉 } \\
\text { Оి } \\
\text { 응 }\end{array}$ & 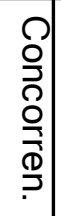 & 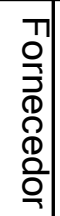 & 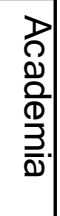 \\
\hline Equipe & 0 & 3 & 2 & 2 & 0 & 2 & 2 & 2 & 2 & 0 & 1 & 0 \\
\hline Bibliotec. & 4 & 0 & 3 & 3 & 0 & 3 & 4 & 2 & 4 & 0 & 1 & 3 \\
\hline Consultor & 2 & 3 & 0 & 3 & 0 & 2 & 3 & 2 & 2 & 0 & 0 & 2 \\
\hline Palestran. & 1 & 1 & 0 & 0 & 0 & 2 & 3 & 0 & 3 & 0 & 0 & 0 \\
\hline Pesquisad. & 0 & 0 & 0 & 0 & 0 & 0 & 0 & 0 & 0 & 0 & 0 & 3 \\
\hline Parceiros & 2 & 2 & 2 & 2 & 0 & 0 & 0 & 0 & 2 & 0 & 3 & 0 \\
\hline Usuários & 4 & 4 & 4 & 4 & 3 & 3 & 0 & 3 & 3 & 2 & 1 & 0 \\
\hline Professor & 1 & 3 & 2 & 0 & 0 & 1 & 3 & 0 & 2 & 3 & 0 & 4 \\
\hline Doadores & 2 & 2 & 1 & 0 & 0 & 0 & 0 & 0 & 0 & 2 & 3 & 0 \\
\hline Concorren. & 2 & 2 & 2 & 1 & 2 & 2 & 3 & 0 & 2 & 0 & 0 & 0 \\
\hline Fornecedor & 0 & 1 & 1 & 0 & 0 & 0 & 0 & 0 & 0 & 0 & 0 & 0 \\
\hline Academia & 3 & 4 & 2 & 2 & 3 & 2 & 2 & 4 & 1 & 1 & 0 & 0 \\
\hline
\end{tabular}

Fonte: elaborado pelos membros da equipe de prospecção com auxílio do software MACTOR, 2016.

Para a elaboração do quadro 08 utilizou-se o software MACTOR, especializado na análise dos jogos de atores, que segundo Godet e Durance (2011, p. 69) "procura avaliar as relações de força entre actores e estudar suas convergências e divergências". Por resultado gerou-se o gráfico 04: 
Gráfico 04 - Mapa de influências e dependências entre atores.

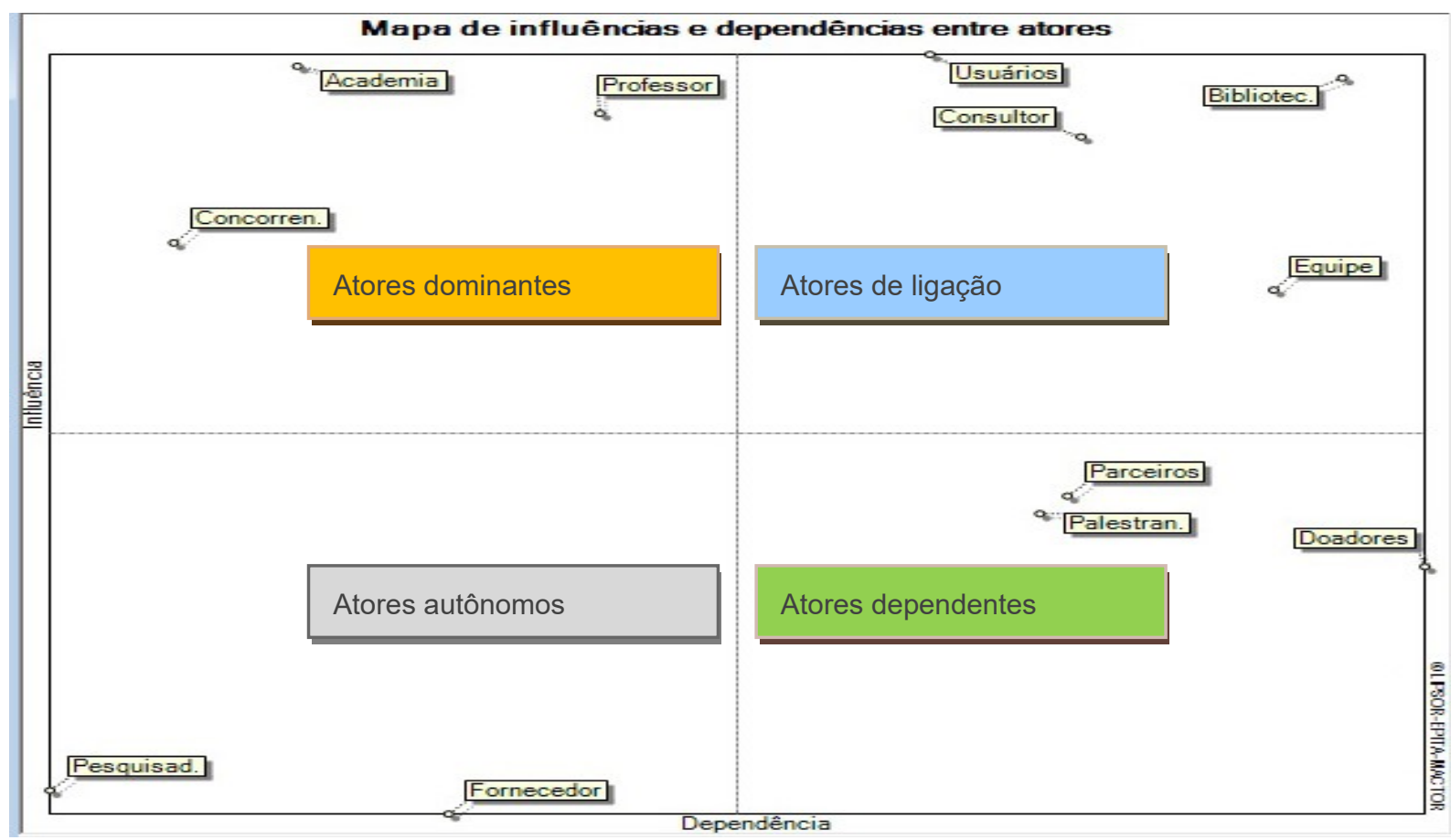

Fonte: gerado pelo sotware MACTOR, 2016.

$\mathrm{Na}$ avaliação do gráfico 04 verificou-se a existência de quatro indicadores, responsáveis por distinguir os atores estudados. Atores dominantes, possuem muita influência, porém pouca dependência: professor, academia e concorrentes. Atores de ligação, exercem influência e emitem dependência num mesmo nível: usuários, bibliotecários, consultor e equipe. Atores dependentes, destacam-se pelo alto teor de dependência e pouca influência: parceiros, palestrantes e doadores. Atores autônomos, para o sistema explicitado, não têm características de influência e dependência suficientes para modificar a dinâmica das relações entre atores: pesquisador e fornecedor.

\subsection{Cenários prováveis}

A última etapa do método é o levantamento de hipóteses que indicarão cenários futuros potenciais. Lidou-se com as variáveis, dos quadrantes superiores: formação, cultura, futuro, necessidade e serviços. Pois elas agem com influência em todo sistema abordado. 
Quadro 09 - Cenários futuros.

\begin{tabular}{|c|c|c|c|}
\hline & o 01 - Dese & jo 02 - Provável & Cenário 03 - Desfavorável \\
\hline Formação & $\begin{array}{l}\text { Coordenações } \\
\text { disciplinas sobre bibliotecas } \\
\text { virtuais nas grades } \\
\text { curriculares dos cursos de } \\
\text { biblioteconomia no Brasil. }\end{array}$ & $\begin{array}{l}\text { Coordenações mantêm } \\
\text { desatualizadas as grades } \\
\text { curriculares dos cursos de } \\
\text { biblioteconomia no Brasil às } \\
\text { bibliotecas que funcionam } \\
\text { em realidade virtual. }\end{array}$ & $\begin{array}{l}\text { Coordenações } \\
\text { desatualizadas as grêm } \\
\text { curriculares dos cursos de } \\
\text { biblioteconomia no Brasil às } \\
\text { bibliotecas que funcionam em } \\
\text { realidade virtual. }\end{array}$ \\
\hline Cultura & $\begin{array}{l}\text { Usuários se adaptam às } \\
\text { tecnologias da realidade } \\
\text { virtual. }\end{array}$ & $\begin{array}{l}\text { Usuários se adaptam às } \\
\text { tecnologias da realidade } \\
\text { virtual. }\end{array}$ & $\begin{array}{l}\text { Falta interesse dos usuários } \\
\text { pelas tecnologias da realidade } \\
\text { virtual. }\end{array}$ \\
\hline Futuro & $\begin{array}{l}\text { Biblioteca virtual Paul Otlet é } \\
\text { reconhecida como uma das } \\
\text { melhores em realidade } \\
\text { virtual até } 2020 \text {. Migra com } \\
\text { sucesso para a plataforma } \\
\text { Sansar. Se adapta às } \\
\text { tendências de realidade } \\
\text { aumentada. }\end{array}$ & $\begin{array}{l}\text { Biblioteca virtual Paul Otlet } \\
\text { migra com sucesso para a } \\
\text { plataforma Sansar. }\end{array}$ & $\begin{array}{l}\text { Biblioteca virtual Paul Otlet não } \\
\text { se adapta à nova plataforma } \\
\text { nem às tendências de } \\
\text { realidade aumentada. }\end{array}$ \\
\hline Necessidade & $\begin{array}{l}\text { Aumenta o número de } \\
\text { frequentadores da Biblioteca } \\
\text { virtual Paul Otlet. }\end{array}$ & $\begin{array}{l}\text { Aumenta o número de } \\
\text { visitantes da Biblioteca } \\
\text { Virtual Paul Otlet, porém não } \\
\text { cresce o número de } \\
\text { recorrências. }\end{array}$ & $\begin{array}{l}\text { Diminui o número de visitantes } \\
\text { da Biblioteca virtual Paul Otlet. }\end{array}$ \\
\hline Serviços & $\begin{array}{l}\text { Os serviços oferecidos são } \\
\text { aprimorados e acrescidos } \\
\text { conforme cresce a demanda } \\
\text { pelo ambiente da Biblioteca } \\
\text { virtual Paul Otlet. }\end{array}$ & $\begin{array}{l}\text { Os serviços oferecidos são } \\
\text { subutilizados pelos visitantes } \\
\text { do ambiente da Biblioteca } \\
\text { virtual Paul Otlet. }\end{array}$ & $\begin{array}{l}\text { Os serviços oferecidos são } \\
\text { subutilizados pelos visitantes } \\
\text { do ambiente da Biblioteca } \\
\text { virtual Paul Otlet. }\end{array}$ \\
\hline
\end{tabular}

Fonte: elaborado pelos membros da equipe de prospecção com base nos mapas extraídos dos softwares MICMAC e MACTOR, 2016.

Três cenários distintos, o desejável exibe hipóteses que promovem o progresso das Biblioteca virtual Paul Otlet e de suas similares ou concorrentes. A variável "Formação", neste cenário, exerce papel fundamental em todo o processo e explica a viabilidade ou inviabilidade da propagação de bibliotecas virtuais em território brasileiro, por isso faz parte das variáveis de entrada, responsáveis por explicar e condicionar todo o sistema. Ainda que a variável "cultura" tenha figurado também no quadrante dos elementos influentes, verificou-se que para alcançar os usuários é necessário investir na formação do profissional. Depende da formação a modificação do ensino e resolução do problema apontado na literatura científica, afinal, a produção literária reflete o conteúdo ministrado em sala de aula. Seu desempenho favorável, ou não, influencia a funcionalidade de todas as outras variáveis constantes nos cenários. Significa dizer que formados profissionais aptos para gerenciar bibliotecas atuantes em realidade virtual, cresce a necessidade pelo uso desses espaços, aumenta, por conseguinte seus serviços, facilita a adaptação dos usuários quanto à utilização dessas ferramentas e oferece crescimento sustentável ao futuro das bibliotecas virtuais. Portanto, se mostram coerentes os dados apresentados pelos gráficos 03 e 04 nos quais "Formação", "Academia" e "Professor" são considerados os elementos influentes na condução do sistema rumo aos futuros prováveis.

\section{Considerações}

A discussão efetuada apontou que bibliotecas atuantes em plataformas de realidade virtual constituem uma tendência recente, ainda não absorvida na formação acadêmica de bibliotecários e demais profissionais da informação no Brasil, conforme apontado por Madureira e Vilarinho (2010) e reforçado através da pesquisa desenvolvida neste trabalho que envolveu a produção literária científica da área Ciência da Informação. Consequentemente a formação acadêmica tornou-se o principal agente influenciador das outras variáveis elencadas. A escassez de profissionais treinados em ambientes virtuais, reflete na relevância que esse tipo de biblioteca, fundamentalmente tecnológica, representa aos seus potenciais usuários. Variáveis que tratam do funcionamento da ferramenta em si, como integridade, competência, atendimento e cooperação foram classificadas na zona das pouco influentes, porque suas adequadas atuações dependem de mudanças 
originárias na formação profissional. Sob entendimento que, apesar de funcionar e ser operante, a Biblioteca Virtual Paul Otlet conseguirá dar continuidade às suas atividades, variável futuro, quando a demanda por bibliotecas virtuais aumentar, inclusive com significativo crescimento de seus concorrentes. Visto que não se trata de uma prática com fins lucrativos, o aumento ou diminuição de usuários e o surgimento ou estagnação de outras bibliotecas virtuais serão consequências das políticas adotadas na fase formativa, por esse motivo os elementos concorrência e atendimento foram alocados ao quadrante das variáveis-resultado. O método utilizado trouxe resultados coerentes na medida em que explicou as lacunas encontradas em dois dos três problemas coletados pelos membros da prospecção, o da produção literária e o cultural, este na perspectiva do hábito e facilidade de uso das tecnologias de realidade virtual.

\section{Referências}

ARAÚJO, Wagner Junqueira. Elementos tecnológicos de edição, manipulação e uso dos livros digitais. Informação \& Sociedade: estudos, João Pessoa, v. 23, n. 01, p. 13-25, jan./abr. 2013. Disponível em: <http://www.ies.ufpb.br/ojs/index.php/ies/article/view/12969>. Acessado em: nov. 2016.

BUARQUE, Sérgio C. Metodologia e técnicas de construção de cenários globais e regionais. Texto para discussão, n. $939, p$. 7-71, 2003. Disponível em: <http://repositorio.ipea.gov.br/bitstream/11058/2865/1/TD 939.pdf>. Acessado em: nov. 2016.

$\mathrm{CAO}$, Mingliang. et al. Creative educational use of virtual reality: working with second life. IEEE Computer Society, vol. $34, \mathrm{n}$. 05, p. 83-87, 2014. Disponível em:

<http://ieeexplore.ieee.org.ez15.periodicos.capes.gov.br/stamp/stamp.jsp?arnumber=6898724>. Acessado em: nov. 2016.

GODET, Michel. The art of scenarios and strategics planning: tools and pitfalls. Technological Forecasting and Social Change, New York, n. 65, p. 3-22, 2000. Disponível em: <http://en.laprospective.fr/dyn/anglais/articles/art of scenarios.pdf> Acessado em: nov. 2016.

GODET, Michel. DURANCE, Philippe. A prospectiva estratégica: para as empresas e os territórios. Paris: DUNOD, 2011. Disponível em: <http://pt.laprospective.fr/download-traducoes/22-file.html>. Acessado em: nov. 2016.

HURST, Paul. CLOUGH, Paul. Will we be lost without paper maps in the digital age? Journal of Information Science, v. 39 n. 1, p. 48-60, 2013. Disponível em: <http://jis.sagepub.com.ez15.periodicos.capes.gov. br/content/39/1/48. full.pdf+html>. Acesso em: nov. 2016

KIRNER, Claudio. SISCOUTO, Robson Augusto. Fundamentos da realidade virtual e aumentada. In: Symposium on virtual and augmented reality, 9., 2007, Petrópolis. Livro do pré-simpósio. Petrópolis: SBC, p. 02-21, 2007.

KIRNER, Claudio. TORI, Romero. Introdução à realidade virtual, realidade misturada e hiper-realidade. In: Symposium on virtual reality, 7., 2004, São Paulo. Livro do pré-simpósio. São Paulo: SBC, p. 03-20, 2004.

KUHN, Thomas Samuel. Estrutura das revoluções científicas. Tradução por Beatriz Viana Boeira, São Paulo: Perspectiva, 1998.

KUMAR, Vineet. et al. A paywall do The New York Times. Harvard Business School Teaching, p. 01-21, 513-p06, jun., 2012.

LANIER, Jaron. An Interview with Jaron Lanier. Interviewed by Adam Heilbrun. Salsalito: Whole Earth, 1989. Disponível em: <http://www.jaronlanier.com/jaron\%20whole\%20earth\%20review.pdf>. Acesso em: nov. 2016.

MONTEIRO, Ana Maria Vieira. Oculus rift como dispositivo cinematográfico: reflexões sobre as potencialidades das máquinas de realidade virtual. Juiz de Fora: UFJF, 2016. Dissertação de mestrado defendida em Comunicação, Universidade Federal de Juiz de Fora, 2016. Disponível em:

<https://repositorio.ufif.br/ispui/bitstream/ufif/1272/1/anamariavieiramonteiro.pdf>. Acessado em: nov. 2016.

MONTEIRO, Bruno. Disrupção digital no marketing e comunicação. UNO, n. 24, 2016. Disponível em: < http://www.revistauno.com.br/wp-content/uploads/2016/01/UNO 24 BR alta.pdf>. Acessado em: nov. 2016.

MORITZ, Gilberto de Oliveira. Planejando por cenários prospectivos: a construção de um referencial metodológico baseado em casos. Santa Florianópolis: UFSC, 2004. Tese de doutorado defendida em Engenharia da Produção, Universidade Federal de Santa Catarina, 2004. Disponível em: <https://repositorio.ufsc.br/xmlui/handle/123456789/86852>. Acesso em: nov. 2016.

NEGROPONTE, Nicholas. Being Digital. New York: Randon House, 1995.

SHERMAN, William R. CRAIG, Alan B. Understanding virtual reality: interface, application, and design. São Francisco: Morgan Kaufmann, 2003. Disponível em: <http://profs. info.uaic.ro/ avitcu/FII\%2020152016/Animatie\%203D Documentatie/VR.pdf>. Acesso em: nov. 2016. 
VARUM, Celeste Amorim. MELO, Carla. Directions in scenario planning literature: a review of the past decades. Futures, v. 42, p. 355-369, 2010. Disponível em: <http://www-sciencedirectcom.ez15.periodicos.capes.gov.br/science/article/pii/S0016328709001955/pdfft?md5=8644d88f82f18d6826b8bd0a1ef77e8b\&p $\mathrm{id}=1-$ 22.0-S0016328709001955-main.pdf>. Acessado em: nov. 2016.

VIGNOLI, Michele Grenge. TOMAEL, Maria Inês. American Library Association (ALA) no Second Life (SL). Perspectivas em Ciência da Informação, v. 17, n.2, p. 92-108, 2012. Disponível em: <http://portaldeperiodicos.eci.ufmg.br/index.php/pci/article/view/1278/1030>. Acesso em: nov. 2016.

WRIGHT, Alex. The role of scenarios as prospective sensemaking devices. Management Decision, v. 43, n. 1, p. 86-101, 2005. Disponível em: <http://www-emeraldinsightcom.ez15.periodicos.capes.gov.br/doi/pdfplus/10.1108/00251740510572506>. Acessado em: nov. 2016.

WULF, Philip Meissner Torsten. The development of strategy scenarios based on prospective hindsight: an approach to strategic decision making. Journal of Strategy and Management, vol. 8, n. 2, p. 176-190. Disponível em: <http://wwwemeraldinsight-com.ez15.periodicos.capes.gov.br/doi/pdfplus/10.1108/JSMA-01-2015-0004>. Acessado em: nov. 2016.

\section{Dados do autor}

\section{Sanderli José da Silva Segundo}

Mestrando pelo Programa de Pós-graduação em Ciência da Informação - UFPB. Graduação em Biblioteconomia (2013).

\section{sannbrownn@gmail.com}

\section{Wagner Junqueira de Araúijo}

Doutor em Ciência da Informação pela Universidade de Brasília - UNB (2009); Mestre em Ciência da Informação - UNB (2001) e Bacharel em Ciência da Computação Pela Universidade do Oeste Paulista (1993). Professor do Programa de Pós-Graduação em Ciência da Informação - PPGCI/UFPB. Professor do Programa de Pós Graduação em Gestão nas Organizações Aprendentes - MPGOA/UFPB. Professor Adjunto IV Departamento de Ciência da Informação da Universidade Federal da Paraíba - UFPB.

wagnerjunqueira.araujo@gmail.com

\section{Guilherme Ataíde Dias}

Pós-Doutor em Ciência da Informação pela UNESP (2011); Doutor em Ciência da Informação pela Universidade de São Paulo - USP (2003) e Graduado em Ciência da Computação pela Universidade Federal da Paraíba UFPB (1990). Bacharel em Direito pelo Centro Universitário de João Pessoa - UNIPE (2010), Mestre em Organization \& Management pela Central Connecticut State University - CCSU (1995). Professor do Programa de Pós-Graduação em Ciência da Informação - PPGCI/UFPB. Professor do Programa de Pós Graduação em Gestão nas Organizações Aprendentes - MPGOA UFPB. Professor Associado I no Departamento de Ciência da Informação da Universidade Federal da Paraíba - UFPB.

guilhermeataide@gmail.com

Recebido - Received: 2017-03-25

Aceitado - Accepted: 2018-01-23 


\section{Notas}

1 Texto original: "Virtual" means something that exists only as an electronic representation, which has no other concrete existence (LANIER, 1989, p. 110).

2 Texto original: Virtual reality is conceived of as an expansion of reality, the provision of alternate realities for people en masse in which to share experiences (LANIER, 1989, p. 112).

3 Site: http://bdtd.ibict.br/

4 Texto original: virtual reality a medium composed of interactive computer simulations that sense the participant's position and actions and replace or augment the feedback to one or more senses, giving the feeling of being mentally immersed or present in the simulation (SHERMAN; CRAIG, 2003, p. 13).

5 Site: http://secondlife.com/

${ }^{6}$ Trecho original: SL offers a ready-made platform for advanced educational use with the potential for many kinds of simulations [...]. It can provide exploration-based activities that epitomize dynamic and active engagement, under authentic learning conditions. It has also been ac $\urcorner$ knowledged as an important tool for supplement $\urcorner$ ing professional training. One academic area that commonly uses SL is design training (CAO; et al., 2014, p. 83).

7 Texto original: En Second Life el representante virtual del usuario es conocido como avatar. El avatar inicialmente es genérico para todos los usuarios, pero una vez empezamos a caminar por Second Life podemos cambiarle absolutamente todo [...] también podemos hacerlo de forma animal o semejante a un monstruo. Second Life nos permite moldear el avatar a nuestro antojo (RODRÍGUEZ, 2007, p. 11).

8 Site: http://www.virtualability.org/

9 Site: http://www.brapci.ufpr.br/brapci/index.php

10 Fanpage da Biblioteca Virtual Paul Otlet: https://www.facebook.com/bibliotecavirtualpaulotlet/?fref=ts

\section{(c) $)$ EY}

This work is licensed under a Creative Commons Attribution 4.0

United States License.

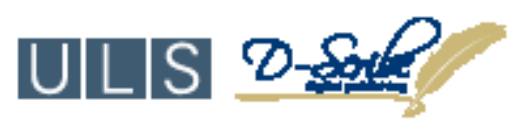

This journal is published by the University Library System of the University of Pittsburgh as part of its D-Scribe Digital Publishing Program and is cosponsored by the University of Pittsburgh Press. 